\title{
Do Mecanicismo ao Selecionismo: Uma Breve Contextualização da Transição do Behaviorismo Radical ${ }^{1}$
}

\author{
Robson Nascimento da $\mathrm{Cruz}^{2}$ \\ Eduardo Neves Pedrosa de Cillo \\ Pontifícia Universidade Católica de Minas Gerais
}

\begin{abstract}
RESUMO - O behaviorismo radical, como filosofia da ciência do comportamento formulada por B. F. Skinner, tem sido desde sua criação alvo de inúmeras críticas e tentativas de rotulação. Dentre as principais críticas está a noção amplamente divulgada de que o behaviorismo radical e sua ciência, análise experimental do comportamento, adotam uma postura eminentemente mecanicista. Para tentar demonstrar o equívoco deste tipo de afirmação, este ensaio busca uma possível interpretação e contextualização do desenvolvimento do behaviorismo radical, no qual se destaca, principalmente, a necessidade de observar que apesar de Skinner ter iniciado seus estudos de psicologia dentro de uma tradição mecanicista, ele cedo adota uma posição que tem como função criticar e afastar-se deste tipo de pensamento.
\end{abstract}

Palavras-chave: behaviorismo radical; mecanicismo; selecionismo.

\section{From Mechanicism to Selectionism: A brief contextualization of the Radical Behaviorism Transition}

\begin{abstract}
The radical behaviorism, as a philosophy of the behavior science formulated by B. F. Skinner, has been a target for endless criticisms and attempts of labeling, since its creation. Among the main criticisms is the widely spread idea that the radical behaviorism and its science, the behavior experimental analysis, adopted an eminently mechanicist posture. Trying to show the misconception of this statement, this essay presents a possible interpretation and contextualization of the radical behaviorism development, where it is mainly highlighted, the need to observe that, although Skinner has started his psychology studies within a mechanicist tradition, he soon adopts a position of criticizing this type of thought, besides presenting as in his science as in his philosophy, a distance each time greater of the mechanicism, and an every time more coherent approach of a selectionist point of view.
\end{abstract}

Key words: radical behaviorism; mechanicism; selectionism.

A história do behaviorismo radical é marcada por polêmicas, incompreensões e contradições apresentadas tanto por seus críticos, quanto por seus adeptos. Entre as possíveis explicações para tantos mal-entendidos, podemos citar a dificuldade de contextualizar o sistema explicativo skinneriano de acordo com seu desenvolvimento histórico, metodológico e conceitual. Desenvolvimento esse que se deu de forma constante entre os anos de 1931 e 1990. Como consequiência desta situação, observamos caracterizações (quase caricaturais) do behaviorismo radical que não levam em consideração as mudanças drásticas, mas que foram construídas de forma gradual, que esse sistema sofreu no curso de seu desenvolvimento.

Uma dessas principais incompreensões está provavelmente vinculada à idéia amplamente divulgada por não-behavioristas de que esta abordagem é conivente com uma visão me-

1 O autor agradece as críticas e sugestões realizadas por Carolina Laurenti da Universidade Federal de São Carlos e pelos pareceristas anônimos da presente revista. Trabalho apresentado junto ao Departamento de Psicologia da Pontifícia Universidade Católica de Minas Gerais - Campus São Gabriel, como monografia para conclusão de curso de graduação em Psicologia sob a orientação do segundo autor.

2 Endereço: Rua Agenor Alves, 68, Bairro Nazaré, Belo Horizonte, MG, Brasil 31990-040.E-mail: robsoncruz78@yahoo.com.br canicista de ciência e homem. Assim, alguns aspectos como certeza absoluta, relações de necessidade e determinismo rígido são citados por muitos críticos como partes constituintes dos fundamentos dessa filosofia e de sua ciência, a análise experimental do comportamento. Neste sentido, a função deste trabalho é apresentar alguns argumentos capazes de mostrar que, apesar de Skinner ter iniciado seus estudos de Psicologia em um contexto mecanicista, e de haver indícios deste modelo em seus trabalhos iniciais, cedo ele demonstra um afastamento desta posição. Isso acontece inicialmente por meio da adoção do conceito de relações funcionais, apresentado pelo físico e filósofo da ciência Ernst Mach e, posteriormente, devido à forte influência do modelo selecionista de Darwin.

\section{A causalidade como o centro das atenções}

Embora a idéia de causalidade seja algo inerente ao conhecimento comum, foi a partir do advento da ciência moderna que ela tornou-se grandemente reconhecida e utilizada. Mais precisamente a partir da Mecânica Clássica Newtoniana, que teve seu ápice em meados do século XIX. Para ter uma noção da influência do mecanicismo sobre o pensamento moderno, Nagel (1961) afirma que: “(...) pensadores destacados tanto físicos como filósofos, sustentavam que a mecânica era a ciência básica e última, e que os 
fenômenos estudados por todas as outras ciências naturais podiam e deviam ser explicadas pelos termos e noções fundamentais da mecânica" (p. 151). Burtt (1932/1983) afirma que o poder do pensamento científico de Newton foi tal que uma série de argumentos apresentados por Newton foram aceitos e reproduzidos acriticamente durante praticamente dois séculos e meio por vários pensadores de diversas áreas do conhecimento. Era como se: "O que Newton não distinguira, outras pessoas não eram capazes de analisar cuidadosamente." (Burtt, 1932/1983, p. 24)

A importância e a influência que o mecanicismo exerceu no pensamento científico moderno serviu como uma espécie de fundamento filosófico e metodológico de todas as demais ciências. De acordo com Rossi (2001):

O método característico da filosofia mecânica na opinião de seus defensores aparece tão poderoso a ponto de ser aplicável a todos os aspectos da realidade: não só ao mundo da natureza, mas também ao mundo da vida, não apenas aos movimentos dos astros e à queda dos corpos pesados, mas também à esfera das percepções e dos sentimentos dos seres humanos. O mecanicismo atingiu também o terreno de investigação da Fisiologia e da Psicologia. (p. 247)

Apesar da influência da Mecânica Clássica demonstrar diferenças nas diversas áreas do conhecimento, como afirma Nagel (1961), algumas noções fundamentais podem ser citadas como características básicas de todas as ciências influenciadas pelo mecanicismo. São elas: a verdade absoluta, as relações de dependência ou de necessidade e o determinismo rígido. A partir destas noções, o mecanicismo se apresenta como um sistema perfeito, que não admite falhas em qualquer uma de suas formulações. A incerteza neste sistema é considerada pura ignorância, ou seja, não há espaço para dúvidas ou falhas. Uma premissa verdadeira sempre deve vir seguida de uma conclusão verdadeira.

O mecanicismo é a pedra angular de praticamente todas as ciências modernas, inclusive da Psicologia. Do modo como a Mecânica adotou a noção de força inicial para explicar o movimento dos corpos, a Psicologia, em suas diversas concepções, recorre a inúmeros eventos antecedentes para explicar o comportamento humano. Desta forma, aquilo que vem antes do comportamento passou a ser utilizado para explicá-lo. Entre estas causas, podemos citar os sentimentos, as emoções, os desejos, a mente, o self, o inconsciente, etc. Por exemplo, quando dizemos que "João brigou com seu irmão porque estava com raiva", o fenômeno (sentimento) interno que surge imediatamente antes do comportamento (brigar com irmão) é visto como a causa do comportamento. A Psicologia, então, volta-se para a busca de causas internas que supostamente antecedem e causam o comportamento.

$\mathrm{O}$ ambiente só parece apresentar alguma importância nas explicações do comportamento, a partir de Descartes. Skinner (1931/1961), ao fazer a descrição histórica do conceito de reflexo, cita Descartes como o primeiro a propor um mecanismo que explicasse a influência de uma parte do ambiente, o estímulo, na determinação do movimento de um animal. Segundo Skinner (1931/1961), Descartes, apesar de ter descoberto um mecanismo (reflexo) pelo qual o movimento de um ser vivo pudesse ser explicado, estava menos preocupado em utilizar o conceito de reflexo como uma relação organismo-ambiente do que fundamentar o papel da alma. Na verdade, Descartes buscava assentar o pensamento de que o estímulo externo agiria de forma direta sobre os órgãos dos sentidos. Assim, os nervos entrariam em contato com o cérebro, que liberaria os espíritos através dos nervos e de sua ação sobre os músculos. Embora Descartes não tenha dado ênfase ao ambiente como fundamental na determinação do comportamento, a partir dele o papel da vontade apresentou grande diminuição nas explicações sobre as causas do comportamento e alguma importância começou a ser dada ao papel do ambiente (Skinner, 1931/1961).

Além do conceito de reflexo, Descartes foi um dos principais responsáveis pelo desenvolvimento do racionalismo moderno. Esta linha de pensamento teve como base o sistema cartesiano, por meio do qual o filósofo propôs formulações para entender o mundo como um grande sistema mecânico capaz de ser analisado pelo estudo de suas partes por meio de operações lógicas do pensamento. Isso significa, numa análise menos aprofundada, que mediante operações lógicas do pensamento conseguimos de forma inequívoca chegar a certas conclusões absolutas acerca de qualquer fato da natureza.

Em contraposição a esta posição, no final do século XVII e início do XVIII, surge o empirismo inglês. Uma das características marcantes desta filosofia é conceber a experiência, e não a razão, como a principal fonte de conhecimento. Esta mudança no fundamento do conhecimento trouxe conseqüências marcantes para o tratamento da causalidade. Tais conseqüências podem ser observadas na crítica feita pelo filósofo David Hume (1711-1776) ao conceito de causalidade como conexão necessária e produto da razão (Laurenti, 2004).

David Hume (1748/1980) traz como um dos seus principais questionamentos a possibilidade do conhecimento a partir de princípios a priori. A posição de Hume implica em uma negação da posição racionalista de Descartes em prol da assertiva de que o conhecimento se dá por meio da experiência. Hume (1748/1980), assim, critica a noção tradicional de causa e efeito, alegando que tanto o conhecimento da causa quanto do efeito são conseqüências da observação habitual de que certos eventos são seguidos por outros eventos, ou seja, do hábito.

Como aponta Laurenti (2004), um dos alvos principais da crítica de Hume em relação à causalidade mecânica está vinculado à noção de conexão necessária, ou relações de necessidade, entre os eventos da natureza, apresentada pelo racionalismo. Segundo Laurenti (2004), a noção de conexão necessária pode ser expressa pelas noções de suficiência e necessidade causal. Assim, um evento é causalmente suficiente para que outro evento ocorra, dado o primeiro, o segundo evento inevitavelmente se segue. A noção de conexão necessária pressupõe uma relação intrínseca entre causa e efeito. Isto significa que todos os eventos da natureza são explicados de forma que uma causa antecedente sempre irá causar um efeito de forma inexorável, ou seja, um evento sempre depende de outro para ocorrer. No entanto, para Hume (1748/1980):

Ao olharmos à nossa volta, para os objetos externos e ao considerarmos a operação das causas, nunca conseguimos, num único caso, descobrir qualquer poder ou conexão necessária e qualquer qualidade que liga o efeito à causa e transforma um em conseqüência infalível da outra. (p. 65). 
O problema das relações de necessidade para Hume (1748/1980) é que a sua aplicação a fenômenos da natureza está baseada em fórmulas matemáticas, de modo que as relações de necessidade são utilizadas como operações lógicas do pensamento para estabelecer as leis da natureza. Porém, segundo Hume (1748/1980), as operações do pensamento, denominadas de relações de idéias, são feitas independentemente dos fatos da natureza, que correspondem às questões de fato.

No campo das relações entre idéias, a verdade e a certeza podem ser alcançadas, pois o conhecimento destas relações se dá via demonstração. Um argumento demonstrativo envolve a noção de dedução e de verdade. Isso quer dizer que a conclusão deste argumento é uma consequiência lógica das premissas, e que essas premissas são necessariamente verdadeiras. Nesta perspectiva, afirmar a verdade das premissas e negar a verdade da conclusão consiste em evidente contradição, já que em um argumento demonstrativo há uma passagem de verdade das premissas à conclusão (C. Laurenti, comunicação pessoal, 30 de julho de 2007). Entretanto, para Hume, o conhecimento das questões de fato não se dá por meio da demonstração. Não é possível justificar logicamente inferências causais. As inferências causais seriam, desta forma, produto do hábito e não da razão ou da demonstração (C. Laurenti, comunicação pessoal, 30 de julho de 2007).

Este breve esclarecimento torna evidente que relações de idéias e relações de necessidade são noções complementares. Mas é fundamental observar que as relações de idéias se dão por meio de operações do pensamento "independente". De forma contrária, as questões de fato, apresentada por Hume (1748/1980), têm como função demonstrar que a natureza deve ser analisada a partir da observação empírica. Para Hume (1748/1980), as questões de fato apontam, no máximo, que certos eventos são mais prováveis de ocorrerem do que outros, já que no passado foi possível observar que certos eventos são, em geral, seguidos por outros eventos.

Portanto, ao contrário do sistema lógico, nas ciências empíricas uma contradição e/ou uma negação são possíveis. Se uma afirmação de fato demonstrar oposição, a sua negação não significa necessariamente uma contradição. Hume (1748/1980):

Todas as demais indagações dos homens só dizem respeito a questões de fato e de existência; e estas, evidentemente, não comportam demonstração. Tudo o que é pode não ser. A negação de um fato jamais poderá envolver contradição. A não existência de qualquer ser, sem exceção alguma, é uma idéia tão clara e distinta quanto a de sua existência. Ainda que falsa, a proposição que nega a sua existência não é menos concebível e inteligível do que aquela que a afirma. O caso das ciências (matemáticas) propriamente dita é diferente. Nelas, toda a proposição que não seja verdadeira é confusa e inteligível. Que a raiz cúbica de 64 seja igual à metade de 10 é uma proposição falsa e nunca poderá ser claramente concebida. Mas que César, o anjo Gabriel ou qualquer outro ser nunca tenha existido, pode ser uma proposição falsa, mas apesar disso é perfeitamente concebivel e não envolve contradição alguma. (p. 203).

Segundo Laurenti (2004), com este tipo de argumento, Hume coloca as questões de fato como campo próprio para o desenvolvimento de uma ciência do homem por meio do uso do método experimental. Hume (1748/1980) afirma claramente que a natureza das evidências (questões de fato) das ciências empíricas é distinta dos objetos (relações de idéias) de investigação das ciências matemáticas.

A despeito destas críticas ao sistema racionalista, realizadas por Hume, podemos supor que foi somente no final do século XIX e início do século XX que o sistema racionalista e mecanicista começou a perder força como modelo predominante de ciência e filosofia. Vários foram os responsáveis por esta transição, mas, como recorte proposto para este trabalho, destacamos o físico e filósofo da ciência Ernst Mach (1938-1916), por ser um importante crítico do sistema mecanicista do final do século XIX e por ser citado por Skinner (1931/1961) como importante influência na formulação de seu sistema explicativo. Só para se ter uma idéia da importância de Ernst Mach no desenvolvimento científico do século XX, Einstein o menciona como fundamental para a formulação da sua Teoria da Relatividade, entre outras coisas, devido às suas formulações críticas ao mecanicismo (Golgher, 1991).

Mach se opôs ao modelo clássico de ciência mecanicista e, entre outras coisas, criticou os limites dos conceitos de causa e efeito, propondo, no lugar da conexão causal, a relação funcional (Laurenti, 2004). Outro ponto importante da obra de Mach parece estar ligado justamente à influência de Hume sobre este autor. Através da leitura da obra "Investigação sobre o entendimento humano" (Hume, 1748/1980), é possível notar a relação direta entre as idéias deste autor e alguns conceitos formulados posteriormente por Mach. Segundo Laurenti (2004), diversas críticas machianas ao sistema mecanicista já haviam sido realizadas por Hume. Aspectos como as limitações da noção de causa e efeito, a proposta de substituição desta noção pelas relações constantes, a crítica à noção de força inicial e a idéia de analisar os eventos como prováveis e não mais como infalíveis - apresentadas por Mach (1893/1960) sob influência de Hume - culminaram na formulação de um de seus conceitos mais importantes: a noção de relações funcionais. Esta noção foi uma proposta que visava substituir as relações de necessidade do sistema mecanicista. Segundo Laurenti (2004), a noção de relações funcionais tem a função de mostrar que a natureza apresenta regularidades passíveis de análise. Assim, em vez de explicar os fenômenos da natureza como relações necessárias entre uma causa e um efeito, Mach (1893/1960) propõe uma descrição dos eventos em termos das funções que estes desempenham uns sobre os outros. O conceito de função irá expressar uma concepção relacional que não tem um fim em si mesma. Na concepção de Mach (1893/1960), não é necessário dizer que um evento causa outro, mas, simplesmente que os eventos são função de outros eventos, dessa forma, um evento influencia a provável ocorrência de outros eventos. Isso significa que o evento antecedente não age mais como uma força inicial, como a causa, mas como parte de uma cadeia de eventos.

Antes de continuarmos nossa exposição, faz-se necessário dizer que estas breves apresentações de alguns aspectos do pensamento humeano e machiano buscaram apontar somente recortes da obra destes autores, com o objetivo de demonstrar uma possível relação desses com o desenvolvimento do behaviorismo radical. 


\section{$O$ conceito de reflexo como fundamento de uma ciência do comportamento: o início do programa científico skinneriano}

Foi em 1931, no artigo: The concept of the reflex in the description of behavior, que Skinner apresentou pela primeira vez sua proposta de um programa de pesquisa. Neste trabalho, Skinner, além de fazer uma revisão histórica do conceito de reflexo, designa tal conceito como base para o estudo do comportamento intacto ou total dos organismos. Nas palavras dele: "Nós estamos tentando enfatizar uma essencial continuidade entre reflexo fisiológico e a descrição de uma ciência especial do comportamento". (Skinner, 1931/1961, p. 344). No mesmo texto, Skinner (1931/1961) ressalta a necessidade de distinção entre as propostas dos dois campos, fisiologia e ciência do comportamento. Para ele, a fisiologia procura investigar os aspectos físico-químicos e a ciência do comportamento estuda a descrição do comportamento em termos de reflexo enquanto uma relação estímulo-resposta. Neste sentido, a base inicial sobre a qual Skinner começa a estabelecer seu sistema explicativo está no conceito de reflexo, mas o objeto de estudo é o comportamento.

Neste ponto, devemos notar que, embora o conceito de reflexo fosse utilizado para análise de um fenômeno fisiológico, a fisiologia se ocupava de supostas causas internas, de modo que parecia não haver uma preocupação com a natureza relacional (ambiente-organismo) deste fenômeno. A inferência a processos internos que ultrapassavam o campo da descrição do comportamento era algo comum naquela época. De outro lado, a ciência do comportamento proposta por Skinner (1931/1961) pretende lidar com a própria observação e descrição do comportamento por meio da análise de uma parte do ambiente, o estímulo e uma parte do comportamento, a resposta do organismo.

\section{O que há de errado com possíveis contradições?}

Neste ponto, chamamos a atenção para o fato de que no programa inicial de pesquisa de Skinner, em 1931, observamos um primeiro e importante "problema": afirmar que Skinner fundamenta seu programa inicial de pesquisa tendo por base o conceito de reflexo tem importantes implicações, tanto no que diz respeito à sua fundamentação epistemológica, quanto ao posterior desenvolvimento do seu sistema explicativo.

Este impasse tem suas origens em duas questões que surgem como centrais no texto de 1931: o conceito de reflexo e a noção de relações funcionais sugerida por Mach, ambas assumidas por Skinner como base para o estudo do comportamento.

No trecho a seguir, tentaremos mostrar que a adoção desses dois conceitos faz surgir uma possível controvérsia. Em 1931, Skinner diz que: “A presente análise do Reflexo como um conceito na descrição do comportamento segue o método primeiro formulado de acordo com os conceitos científicos de Mach e Poincaré"'. (Skinner, 1931/1961, p. 345). Nesta passagem, Skinner inclui Mach e Poincaré, importantes críticos do sistema mecanicista do final do século XIX, no mesmo campo do conceito de reflexo, um autêntico representante da tradição mecanicista. De acordo com Sério (1990), é justamente quando Skinner inicia seus estudos em Psicologia, no final dos anos 1920, que o conceito de reflexo sofre inúmeras críticas e objeções. Além de ser incompatível com a proposta de Mach, parece ser anacrônica, como sugestiona Sério (1990), a tentativa de Skinner de utilizar o conceito de reflexo como central em sua ciência do comportamento.

Embora não seja nosso objetivo descrever a história do conceito de reflexo nem suas diversas definições, é necessário dizer que tal conceito carrega marcas indeléveis de seu compromisso com a tradição mecanicista de ciência. Para o campo de interesse deste trabalho, destacamos, então, as relações de necessidade como a principal categoria, marca do conceito de reflexo a ser analisada neste momento, com objetivo de contrapô-la com a noção de relações funcionais.

A proposta inicial de Skinner (1931/1961) destaca que o conceito de reflexo seja utilizado na descrição do comportamento, por meio da noção de relações funcionais. Relembramos que a noção de relações funcionais proposta por Mach (1893/1960) tem como fundamento a noção Humeana de que não podemos afirmar que um evento causa inexoravelmente outro, mas somente que percebemos que certos eventos são seguidos por outros eventos semelhantes, em determinadas ocasiões. De acordo com Laurenti (2004):

Adianta-se aqui uma aproximação de Hume tanto com Mach quanto com Skinner. Estes últimos também recusam as noções de força ou agência, o primeiro no campo da Física, o segundo, no campo da Psicologia para deterem-se nas relações constantes ou, posteriormente, relações funcionais. (p. 32).

Ou seja, a noção de relações funcionais que perpassa a obra de Mach e Skinner traz uma crítica explícita à noção de força inicial.

Além da contradição que Skinner (1931/1961) parece apresentar em seu programa inicial, outra suposta contradição específica surge quando Skinner propõe um método descritivo para análise de um conceito (reflexo) que é explicativo e tem um fim em si mesmo. Nas palavras de Skinner: "Como uma disciplina científica, é necessário não descrever o evento somente por si mesmo, mas em sua relação com outros eventos." (Skinner, 1931/1961, p. 337). No parágrafo seguinte ele diz: "O reflexo é importante na descrição do comportamento porque este é definido pela demonstração da necessidade desta relação" (Skinner, 1931/1961, p. 338). Disso resulta que ao mesmo tempo em que Skinner assume que os eventos não devem ser vistos de forma necessária, em seguida dá pistas de que o reflexo é importante porque é possível defini-lo pela demonstração da necessidade de sua relação. Neste ponto, é inevitável perceber que há algo de incompatível nestas passagens, o conceito de reflexo e sua característica básica (relações de necessidade) são incompatíveis com a noção de relações funcionais.

Skinner (1931/1961) parece escolher dois conceitos incompatíveis para fundamentar seu programa inicial de pesquisa. Todavia, nem toda incompatibilidade é prejudicial e/ou incoerente, podemos dizer que este possível "erro" epistemológico cometido por Skinner (1931/1961) pode ser visto como uma "Contradição Epistemológica Positiva". É contradição porque Skinner apresenta um conceito mecanicista como base para suas formulações iniciais de uma ciência do comportamento, ao mesmo tempo em que adota a noção de relações funcionais como modelo de análise causal. E é 
positiva, porque parece demonstrar aquilo que Abib (2004) chamou de posição transgressora, que Skinner apresentou durante toda sua obra. Neste caso específico, esta transgressão revela que Skinner começa seu trabalho dentro de uma posição mecanicista, mas, ao mesmo tempo, já apresenta uma posição que tem como função substituir e/ou ultrapassar este mesmo sistema.

\section{Uma breve, mas necessária, revisão da primeira década}

Mesmo sendo nosso objetivo principal situar alguns aspectos da transição do behaviorismo radical, não temos espaço e nem condições de detalhar a complexa construção do sistema explicativo skinneriano neste breve trabalho. Contudo, mesmo que de forma breve, faremos aqui uma espécie de resumo da primeira década de seu programa de pesquisa e de como ele enfrentou a contradição exposta acima. Para isso, apresentaremos uma breve descrição de alguns dos aspectos que parecem revelar as dificuldades enfrentadas por Skinner no início de sua obra.

De acordo com Sério (1990), após 1931, Skinner começa a notar certa dificuldade em estudar o comportamento em termos de S-R. Isso porque Skinner extrapola os limites do conceito de reflexo e começa a dar atenção a processos que são analisados a partir da resposta. A própria preocupação direcionada para a resposta em si é um exemplo desta extrapolação em direção a sua principal formulação: a noção de operante, já que estudar ou descrever o comportamento em termos de reflexo implica estudar a relação estímulo-resposta, e não só a resposta. Essa atenção direcionada à resposta se deve a um dos problemas enfrentados por Skinner, dentre os quais podemos citar a variabilidade apresentada no Reflexo Tipo I. Apesar de não nos aprofundarmos nesta questão, é importante dizer que, durante o período de 1931 a 1938, o conceito de reflexo no sistema explicativo skinneriano foi utilizado para designar tanto o Reflexo Tipo II (respondente) quanto o Reflexo Tipo I (futuro operante). Mas o problema com a variabilidade vai estar relacionado apenas ao Reflexo Tipo I. Isso porque, o problema com a variabilidade no Reflexo Tipo II (respondente) já havia sido resolvido com a descoberta das leis primárias (limiar, magnitude, latência, pós-descarga, somação tempo real) e secundárias ou dinâmicas do reflexo (fadiga do reflexo, facilitação, inibição, fase refratária, condicionamento, extinção). Este problema foi resolvido com a adoção da noção de classe de respostas e classe de estímulos. Essas noções, mais o efeito que uma resposta produz no ambiente, demonstraram que a variabilidade era parte do processo comportamental, e não algo inexplicável e à parte da situação. Ou seja, nesta suposta variabilidade do comportamento dito voluntário, Skinner começou a notar a regularidade do comportamento que não era semelhante àquela apresentada pelo modelo $\mathrm{S}-\mathrm{R}$.

Skinner (1935, 1938/1966) passa, então, a lidar com o Reflexo Tipo I como aquele que produz efeito no ambiente. Isso coloca a ênfase da pesquisa na resposta e na conseqüência, o que excede os limites do conceito de reflexo (Sério, 1990). Surge, então, uma operação inversa ao reflexo tradicional: a operação R-S (resposta-estímulo reforçador).

Segundo Sério (1990), estas questões parecem forçar a ruptura com o conceito de reflexo, necessidade óbvia a partir da análise do fenômeno R-S. Contudo, Skinner durante pra- ticamente toda a década de 1930 não desvincula o Reflexo Tipo I da noção de reflexo, mesmo sendo esta noção limitada à sua descoberta (Sério, 1990).

Skinner (1938/1966) em "The behavior of Organisms" - trabalho que apresenta um detalhado relato das pesquisas que o levam a formulação do conceito de operante -, passa a diferenciar comportamento respondente de comportamento operante, mas utiliza-se ainda do termo reflexo para incluir ambos os comportamentos, embora em seu significado original seja aplicado apenas ao respondente.

Uma das explicações para a dificuldade em estabelecer a distinção entre respondente e operante pode estar ligada ao fato que uma desvinculação do conceito de reflexo implicaria uma ruptura com um modelo filosófico e científico, algo que Skinner já estava fazendo desde 1931. Segundo Sério (1990):

(...) a tentativa de Skinner de estender o conceito de reflexo ao comportamento total de organismos intactos carrega junto uma determinada concepção sobre o processo de produção de conhecimento científico; seu programa de investigação parece ter um pé fincado nesta concepção e outro fincado no conceito de reflexo, e a extensão deste programa não deixam imunes nem o conceito de reflexo, nem o conceito ao qual ele dá origem -o conceito de operante (p. 160).

Mesmo sendo o conceito de reflexo um compromisso no sistema explicativo skinneriano, à medida que seu programa de pesquisa se desenvolve, torna-se cada vez mais difícil (impossível) mantê-lo. É então evidente que a definição de reflexo não mais suporta a extensão que o programa científico de Skinner alcança, ou seja, não existe reflexo ou é inadequado um reflexo que tem a resposta como a fonte de análise. Como aponta Sério (1990):

O projeto inicial de Skinner de estender o conceito de reflexo ao comportamento total o conduz a um tipo de comportamento que não cabe dentro do paradigma do reflexo, seu compromisso com este projeto parece obrigá-lo a manter o conceito e seu paradigma: o $\boldsymbol{S}$ (estímulo) se mantém mesmo quando não tem mais sentido algum, o operante é dito um tipo de reflexo mesmo não havendo um reflexo no caso do operante (p. 174).

Portanto, é plausível supor que Skinner não mais estivesse preocupado com o $\mathrm{S}$, o que indica que, mesmo que ele ainda não tenha declarado sua ruptura com a noção de $S-R$, já havia abandonado o estímulo antecedente como a principal variável a ser investigada. A partir disso, Skinner começa a esboçar a idéia de um comportamento que não depende exclusivamente de um evento anterior.

Outro ponto de fundamental importância na primeira década do programa científico skinneriano é que (Skinner, 1938/1966) assume que a medida de análise do Reflexo Tipo I é a taxa de resposta. Isso deixa claro que uma das principais características do operante é justamente sua não eliciação. Para Sério (1990), esse é outro aspecto que torna o operante inconcebível ou incompatível com a noção de reflexo. Nas palavras da autora, "(...) Skinner irá reconhecer que a taxa é uma medida adequada para comportamentos não eliciados, entretanto, ele a propõe quando ainda acreditava que todos os comportamentos são eliciados." (Sério, 1990, p. 284). 
Com este breve resumo, observa-se que na década de 1930, Skinner teve de lidar com as questões anteriormente mencionadas, até a formulação do conceito de operante. Mas é necessário notar que estes possíveis problemas não devem ser analisados como algo negativo. Isso porque é justamente a partir dessas aparentes contradições que Skinner consegue desenvolver um sistema explicativo que volta sua atenção para as contingências de reforçamento, e não mais somente para os eventos imediatamente antecedentes ao comportamento.

Feyerabend (1975/1977), ao analisar períodos conturbados da construção de sistemas científicos, afirma que é comum o uso de expressões já existentes em períodos de transição, o que acarreta em certa medida uma linguagem imprecisa para o fenômeno que se investiga, algo que ocorreu com Skinner. Feyerabend (1975/1977) esclarece que

(...) uma teoria pode ser incompatível com a evidência não por encerrar incorreção, mas porque a evidência está contaminada (...) ou porque é apresentada nos termos de concepções antiquadas ou porque é avaliada com base em elementos auxiliares já não válidos. (p. 89).

Pode-se dizer, então, que não há problema algum em notar supostas incompatibilidades e/ou contradições na proposta inicial do programa científico Skinneriano, quando Skinner recorrer ao conceito de reflexo para se referir ao operante, já que esta posição, ou, como diria Feyerabend (1975/1977), este procedimento anárquico, foi fundamental para que Skinner cada vez mais se afastasse de uma posição mecanicista.

\section{O comportamento operante: a caminho de uma explicação complexa do comportamento}

O que vimos até agora foi a luta inicial de Skinner para conseguir afastar seu programa de pesquisa de uma posição mecanicista. Esse conflito inicial começou a ser superado somente depois que Skinner assumiu o condicionamento operante como um processo distinto do condicionamento reflexo. A descrição do período exato em que esta ruptura acontece não é unanimidade entre os diversos intérpretes do pensamento skinneriano. Mediante a dificuldade de se encontrar o trabalho que defina este rompimento de forma exata, Moxley (1999) sugere que a melhor forma de definir esta transição é por meio da análise de alguns conceitos e trabalhos de acordo com seu período de desenvolvimento histórico-conceitual. Isso porque, segundo esse autor, é possível observar tanto características mecanicistas quanto selecionistas em um mesmo trabalho de Skinner, em períodos anteriores e posteriores à adoção da noção de operante. Então, o melhor procedimento é apresentar a obra de Skinner como um caminho que se afasta do mecanicismo de forma gradual e se aproxima cada vez mais do selecionismo, ao invés de apresentar um ponto exato no qual este rompimento aconteça.

Contudo, Moxley (1999) ressalta que a publicação, em 1945, do artigo: "The Operational Analysis of Psychological Terms" é fundamental para as transformações do sistema explicativo Skinneriano. Isto porque é nesse trabalho que Skinner propõe, pela primeira vez, uma interpretação de eventos privados a partir da noção de contingências de três termos. Disso decorre, uma análise selecionista do fenômeno da subjetividade, fenômeno este descartado ou explicado por vias mentalistas pelos behavioristas daquele período. Além disso, historicamente é nesse trabalho que Skinner denomina sua posição de behaviorista radical.

Pela extensão do tema proposto, tentaremos a partir deste ponto apresentar características do behaviorismo radical que demonstrem sua transição. Para isso, retomaremos a causalidade como centro da nossa exposição, posto que tal aspecto parece desenvolver papel central na presente discussão.

\section{Causas ou determinantes do comportamento?}

A despeito de ainda não analisarmos que modelo de determinismo é adotado por essa filosofia, não seria possível argumentar ou, quem sabe, até afirmar que toda tentativa de explicar qualquer aspecto do comportamento humano assume também alguma instância ou fenômeno determinante? A mente, a vontade, o self, o desejo, a alma, os astros e a liberdade não seriam aspectos determinantes utilizados em diversas explicações, inclusive científicas?

Neste sentido, podemos dizer que diminuir o valor ou criticar qualquer teoria científica ou filosófica simplesmente por ela ser determinista não pode ser considerada uma crítica válida em si. Este tipo de argumento é, em geral, uma tentativa esdrúxula de fazer uma teoria parecer inferior em prol de outra. Isso também faz com que o determinismo em si pareça algo negativo. Entretanto, como já citado, o determinismo é inerente ao método científico, mesmo quando algumas teorias alegam que os homens são movidos por suas mentes, vontades, etc, mas devemos notar que não há somente uma forma de determinismo. São incontáveis os tipos de determinismo nas diversas áreas do conhecimento científico e filosófico, e até mesmo dentro de uma mesma área, como no caso do behaviorismo, é possível encontrar enormes diferenças entre os tipos de determinismo assumidos entre suas diversas abordagens.

Nas ciências físicas, químicas e biológicas o determinismo sempre foi aceito e a ele foi atribuído muito do sucesso dessas ciências. Contudo, quando o objeto de estudo é o comportamento humano, a adoção de uma tese determinista sofre, continuamente, grande resistência. A discussão sobre a determinação do comportamento é antiga e polêmica, porque esta perspectiva é vista, na maior parte das vezes, como antagônica ao livre-arbítrio. Para Blanshard (1958/1974):

O homem comum não se opõe ao determinismo quando aplicado pelos físicos aos átomos; ou por ele próprio às máquinas; ou pelo médico ao seu próprio corpo. Mas ele se opõe tenazmente quando aplicado por quem quer que seja ao seu pensamento e ao seu arbítrio (p. 27).

Outro problema comum está vinculado à idéia de um fatalismo, como se o comportamento seguisse um destino inevitável. Porém, não é esta a perspectiva determinista apresentada pelo behaviorismo radical. Tal perspectiva assume apenas que “(...) todo comportamento possui uma causa, conhecida ou não, identificável ou não pelas técnicas e procedimentos usuais, mas certamente existente" (Carrara, 1998, p. 46). 
Embora só o termo determinismo tenha aparecido nesta parte de nosso trabalho, devemos esclarecer que a palavra determinismo é, neste caso, sinônimo de causalidade. A despeito de Skinner dar preferência ao termo "determinantes do comportamento" em vez de "causas do comportamento". Como apontam (Andery \& Sério, 2001) e (Laurenti, 2004), esta posição deve-se ao histórico do termo causa, que tem a conotação de um agente iniciador, ou força inicial, comum nas explicações mecanicistas. Mas isso não quer dizer que Skinner não procure as causas do comportamento. Na verdade, o que Skinner (1953/2000) evidencia é uma preocupação em demonstrar que estas causas são estabelecidas na interação do organismo com o ambiente. Deste modo, não há problema em dizer que o analista do comportamento procura as causas do comportamento, desde que se considere que “(...) a causa não está fora, não existe à parte do evento estudado, mas sim está no próprio evento, é parte dele". (Andery \& Sério, 2001, p. 160). O que significa que o termo causa no behaviorismo radical e na análise do comportamento só deve ser utilizado na explicação do comportamento se fizer parte da descrição e explicação dos eventos que o constituem. Ou seja, identificar as causas do comportamento é fazer a descrição mais completa possível das relações funcionais e explicar estas relações de acordo com suas consequiências passadas.

\section{Selecionismo e Determinismo probabilístico}

No início da década de 1930, apesar de ainda não ter formulado a noção de operante, Skinner (1935, 1938/1966) já assume, mesmo que de forma discreta, uma postura selecionista, como apontam Andery (1997), Micheletto (2001) e Moxley $(1999,2001)$. O que implica, em um probabilismo, mesmo que não explícito. Mas, a partir da adoção do condicionamento operante como base de suas formulações, Skinner postula de forma definitiva e explícita que o comportamento operante deve ser analisado em termos de seleção e probabilidade de emissão de respostas. Esta posição tem várias implicações, uma delas é a influência de Darwin sobre o pensamento skinneriano como marca que será desenvolvida durante toda a sua obra. Outra consequiência é que embora a noção de seleção natural não seja incompatível com uma explicação mecanicista, como próprio Skinner (1981/1984) apresentou ao criticar o termo "pressão seletiva" como uma tentativa da causalidade mecânica clássica explicar a seleção. A incompatibilidade do modelo explicativo skinneriano com um modelo mecânico de causalidade não parece ser reduzido à idéia de seleção, mas, sim, como este processo ocorre na determinação do comportamento. Neste caso, o comportamento não é pressionado a agir de determinada maneira, ele é selecionado pelas suas conseqüências, aumentando a probabilidade de ocorrência de uma dada classe de respostas (C. Laurenti, comunicação pessoal, 30 de julho de 2007).

Portanto, uma das principais implicações das questões tratadas acima é que Skinner (1981/1984) confere ao condicionamento operante importante semelhança com a seleção natural. Para ser mais específico, o condicionamento operante é visto como parte da seleção natural. Nas palavras dele, " $O$ condicionamento operante é seleção em progresso" (Skinner, 1981/1984, p. 502). Logo, como a teoria darwinista, o condicionamento operante não tem um plano ou propósito.
Outro aspecto a ser notado é que, tanto na seleção natural quanto no condicionamento operante, a adoção de uma tese determinista e probabilística não significa de forma alguma que Darwin e Skinner deixaram espaço para uma criação divina, no caso da seleção natural, ou um agente iniciador, no caso do condicionamento operante, por não conseguirem prever exatamente quando e como uma variação e seleção da espécie e do comportamento ocorrerá. Como aponta Moxley (1999), não saber o resultado de uma variação e seleção tanto da espécie quanto do comportamento, a priori, não os torna livres de estarem submetidos a leis preexistentes. Esta proposição não deixa espaço para alguma instância sobrenatural ou mental como parte da determinação do comportamento. Mesmo que a explicação em alguns casos seja realizada $a$ posteriori.

Uma descrição das propriedades do estímulo antecedente na explicação do comportamento operante será útil para ilustrar como a noção de condicionamento operante afasta-se de uma perspectiva mecanicista. Nesta perspectiva, o estímulo antecedente passa a ser visto como parte da contingência, não como o determinante principal. Portanto, o estímulo antecedente perde seu status de força inicial e adquire as seguintes características: 1) passa a ser visto dentro de um contexto e não mais independente dele, como no reflexo; 2) só pode ser analisado em relação à história de reforçamento do organismo; 3) um mesmo estímulo antecedente pode apresentar funções diferentes ou mudar de função de acordo com a história de reforçamento; 4) não elicia uma resposta, mas simplesmente aumenta a probabilidade dessa ocorrer novamente.

Outro aspecto importante diz respeito à idéia de probabilidade de emissão de respostas, que é amparada pelo pressuposto de que o comportamento é provável porque as contingências sempre vêm primeiras e são probabilísticas (Moxley, 1999). Ou seja, o comportamento não é probabilístico em si mesmo, mas apenas em sua relação com o ambiente que apresenta certa regularidade. Para lidar com essa regularidade Skinner (1969/1984) diz que: "Um dado natural numa ciência do comportamento é a probabilidade de determinado fragmento (bit) de comportamento ocorrer num dado momento. A análise experimental lida com tal probabilidade em termos de freqüência de respostas" (p. 231). Portanto, se uma resposta é emitida com alta freqüência, essa tem maior probabilidade de ser selecionada e ocorrer em uma ocasião similar no futuro. Mas é preciso notar que probabilidade e freqüência de respostas só se tornaram noções úteis e confiáveis porque foi possível, por meio da metodologia da análise experimental do comportamento, especificar a topografia da resposta e contar um determinado operante (pressão a barra) (Skinner, 1969/1984). Skinner desta maneira estabeleceu uma forma de mostrar a frequiência e, logo, a probabilidade de emissão de uma resposta. Esta demonstração é feita por meio da análise da taxa de respostas. Essa, na prática, revela que determinadas respostas apresentam uma uniformidade considerável em determinadas condições ambientais (Skinner, 1969/1984). No entanto, não é postulado que há uma regularidade rígida ou inexorável do comportamento quando a frequiência de uma resposta é observada e analisada. $\mathrm{Na}$ verdade, ela irá demonstrar diferentes regularidades do comportamento de acordo com os diferentes esquemas de reforçamento ao qual o organismo foi exposto. 
Laurenti (2004), ao apresentar possíveis influências do pensamento de Mach sobre Skinner, afirma que para Mach, a probabilidade está relacionada a uma concepção de que há no mundo regularidades ou relações constantes, mas que essas são mutáveis e probabilísticas. Por conseguinte, se é assumido que os eventos da natureza apresentam relações constantes e que estas relações são probabilísticas, não seria válido, então, supor que o determinismo probabilístico no behaviorismo radical obtém um conhecimento parcial ou incompleto. Laurenti (2004) tenta esclarecer isso ao dizer que "Nesta proposta, o determinismo poderia ser tratado no contexto de um instrumentalismo, sendo encarado como uma regra ou princípio regulativo da pesquisa" (p. 135). Isso implica que o pesquisador aceita a noção de probabilidade como inerente ao seu objeto de estudo e à sua própria pesquisa. Entretanto, aceitar a probabilidade não exclui a possibilidade de previsão e controle do comportamento, já que, como explicitado anteriormente, Skinner conseguiu demonstrar empiricamente que o comportamento apresenta certa regularidade passível de ser investigada por meio da análise da taxa de respostas.

A noção de classe de respostas é outro conceito fundamental para entendermos melhor o determinismo probabilístico, porque demonstra que um operante é formado através da ocorrência de várias respostas que são reforçadas diferencialmente. Então, a probabilidade não se restringe a uma única resposta, mas a várias respostas similares àquelas que foram reforçadas. De acordo com Skinner (1953/2000):

Uma resposta que já ocorreu não pode, é claro, ser prevista ou controlada. Apenas podemos prever a ocorrência futura de respostas semelhantes. Desta forma, a unidade de uma ciência preditiva não é uma resposta, mas sim uma classe de respostas. Para descrevermos esta classe usar-se-á a palavra operante. (p. 71).

Essa noção é mais um exemplo que certifica o afastamento de Skinner da procura por relações de necessidade entre um estímulo e uma resposta. E amplia as possibilidades de observar o comportamento operante como um comportamento complexo que não é explicado por meio de relações rígidas e simplificadas com o ambiente.

\section{O modelo de seleção por conseqüências}

Todas as questões apresentadas até aqui representam em certa medida a formulação de um modelo causal único, o modelo de seleção pelas consequiências, modelo este que marca de forma decisiva a desvinculação do behaviorismo radical ao mecanicismo e destaca, ao mesmo tempo, uma posição eminentemente selecionista. Este modelo pode ser descrito como a maior evolução no desenvolvimento do sistema explicativo skinneriano.

Este modelo pode ser visto como uma espécie de analogia entre o condicionamento operante e a seleção natural das espécies (Dittrichi, 2004). Desta maneira, a causalidade passa a ser descrita por dois processos básicos apresentados pela teoria da seleção natural darwinista, sendo eles a variação e a seleção. E, como característica específica do modelo de seleção por consequiência, Skinner (1981/1984) formula três níveis de seleção do comportamento. São eles: a filogenia, a ontogenia e a cultura. A filogenia é caracterizada pelas contingências de sobrevivência da espécie. O segundo nível, a ontogenia, está relacionado à história de reforçamento do indivíduo, ou seja, às contingências de reforçamento experimentadas por um único organismo, durante o seu tempo de vida. $\mathrm{O}$ terceiro nível é o cultural, no qual estão presentes as contingências sociais.

A filogenia, como primeiro nível de seleção, é fruto de milhões de anos de evolução. Este nível de seleção é responsável pelo desenvolvimento de aspectos anatômicos, fisiológicos e neurológicos, como também pelo surgimento e evolução de uma série de padrões comportamentais, por exemplo, os respondentes e os operantes (Andery, Micheletto \& Sério, 2002). Para Skinner (1974/2002), "O fato de o condicionamento operante, como todos os processos fisiológicos, ser um produto da seleção natural, lança luz sobre a questão de quais tipos de conseqüências são de reforço e por quê." (p. 43). O condicionamento operante é considerado por Skinner (1974/2002) um processo que suplementa a seleção natural. Isso porque a filogenia, como produto de contingências de sobrevivência da espécie, desenvolve-se em períodos de milhões de anos, o que propicia falhas na seleção do comportamento, uma vez que o comportamento foi selecionado para ser adaptado em um ambiente que não existe mais, já se transformou. Neste caso, o condicionamento operante tem como função estabilizar a ação do organismo sobre o ambiente atual. De acordo com Skinner (1974/2002):

Conseqüências importantes do comportamento, que não poderiam desempenhar um papel na evolução, porque não constituem traços suficientemente estáveis do meio, tornam-se eficazes, por intermédio do condicionamento operante, durante a vida do indivíduo, cujo poder de haver-se com seu mundo é assim grandemente ampliado (p. 43).

A partir do condicionamento operante, surge o segundo nível de seleção: a ontogenia, que tem como característica básica a suscetibilidade do organismo às conseqüências de sua ação. Isso quer dizer que cada organismo, independentemente da espécie, é modificado pelas conseqüências de suas ações sobre o ambiente, o que acarreta respostas únicas e, por conseguinte, repertórios comportamentais singulares. No caso do comportamento humano, isso culmina naquilo que Skinner (1989/1991) chama de pessoa, porque nenhum sujeito vai apresentar uma história ontogênica idêntica, mesmo sendo submetido aos processos de seleção e variação como qualquer outro membro da espécie (Andery \& cols., 2002).

A suscetibilidade às conseqüências da ação do organismo sobre o ambiente como característica básica do segundo nível de seleção implica que o comportamento mantém uma interação constante de controle com o ambiente. Mas, para o surgimento do terceiro nível (cultura), devemos considerar que outros indivíduos fazem parte deste ambiente e exercem controle entre si. Como apontam Andery e cols. (2002), nesta relação, um indivíduo pode ser para outro indivíduo um estímulo antecedente e/ou conseqüente, que faz parte de processos como a imitação e a modelagem do comportamento controlado por regras ou por contingências. 
Assim, para o aparecimento desse terceiro nível, Skinner (1981/1984) ressalta o papel fundamental do surgimento do comportamento verbal na espécie humana, uma vez que por meio dele é possível a transmissão de práticas que garantem a sobrevivência da cultura. Porém, para considerarmos tal argumento, é preciso notar que, neste nível de seleção, ao contrário dos dois primeiros, o efeito sobre o indivíduo não é responsável pela sua evolução, mas sim o efeito sobre o grupo, o que possibilita a variação e seleção de práticas culturais. Para Skinner (1981/1984):

Em resumo, o comportamento humano é um produto da junção de (I) as contingências de sobrevivência responsáveis pela seleção natural das espécies e (II) as contingências de reforço responsáveis pelos repertórios adquiridos pelos seus membros, incluindo (III) as contingências especiais mantidas por um ambiente social evoluído. (Definitivamente, é claro, tudo isso é uma questão de seleção natural, uma vez que o condicionamento operante é um processo evoluído, no qual as práticas culturais são aplicações especiais). (p. 503).

É importante esclarecer que o modelo de seleção por consequiências não deve ser visto de forma dividida ou hierárquica, como se houvesse a sobreposição de um nível sobre o outro. Pelo contrário, este modelo só pode ser utilizado como um instrumento de interpretação e explicação do comportamento se levarmos em consideração sempre os três níveis de seleção conjuntamente, muito embora cada nível de seleção apresente suas disciplinas específicas, no primeiro, a biologia; no segundo, a psicologia; e no terceiro, a antropologia (Skinner, 1981/1984).

Esta breve exposição do modelo de seleção por conseqüências teve como função deixar nítido o nível de complexidade que o sistema explicativo skinneriano atingiu. Outro objetivo da apresentação deste modelo foi mostrar que Skinner não somente utiliza-se de conceitos desenvolvidos com fundamento na observação e na experimentação para explicar o comportamento. Ele também desenvolve ferramentas conceituais, que não são necessariamente produtos diretos da experimentação, para interpretar comportamentos complexos. O que mostra uma importante afinidade do modelo explicativo skinneriano com o instrumentalismo científico, que, entre outras coisas, concebe os conceitos científicos como ferramentas que direcionam a ação do cientista (Laurenti, 2004).

\section{A transição já havia começado}

Um exame das questões tratadas até aqui possibilitou algumas conclusões. A primeira delas é que a transição mecanicismo/selecionismo é uma característica do sistema explicativo skinneriano desde suas primeiras formulações. Embora Skinner recorra em grande parte ao conceito de reflexo como unidade de análise em sua formulação inicial, é evidente que a noção de relações funcionais e suas descobertas empíricas deixam-no cada vez mais longe de uma formulação mecanicista do comportamento.

Desta forma, a transição do behaviorismo radical, de uma posição mecanicista para uma selecionista, é reflexo de suas formulações empíricas e de sua concepção teórica de ciência, destacadas neste artigo pela influência de Ernst Mach e da teoria da evolução.

Em relação às formulações do programa inicial de pesquisa skinneriano e à noção de causalidade, observamos que o abandono do conceito de reflexo como base para uma ciência do comportamento e a adoção do condicionamento operante como foco do programa de pesquisa skinneriano fazem com que Skinner renuncie às relações de necessidade e assuma a noção de relações funcionais e de probabilidade de respostas. Contudo, a noção de relações funcionais parece sofrer alterações à medida que o sistema explicativo skinneriano se desenvolve. Esta noção inicialmente tem a dupla função de descrever e explicar o comportamento. Skinner (1931/1961) deixa claro que descrever é explicar. Portanto, descrever as relações funcionais do comportamento significava explicar o comportamento. Este posicionamento pode ser entendido como o primeiro e fundamental rompimento do sistema skinneriano com a noção de causalidade mecânica, mesmo apresentando os problemas iniciais que já foram discutidos. Como aponta Laurenti (2004):

A explicação no Behaviorismo Radical não se identifica com explicação causal. Essa desvinculação da explicação científica com a noção de causalidade se deu através das relações indiretas com Hume. Skinner (1953, 1969) incorporou, via Mach, a crítica humeana à idéia de conexão necessária e rejeitou as noções relacionadas a este modo causal, como os conceitos de força ou agência. (p. 53).

Todavia, argumenta-se a partir de indícios apresentados no decorrer do artigo, que Skinner pode ter ido além da crítica de Hume e Mach, e ter alterado a idéia presente em seus trabalhos da década de 1930 de que descrever e explicar são aspectos semelhantes. A partir da adoção de uma posição eminentemente selecionista, descrever e explicar deixariam de ser utilizados como noções semelhantes, mas, sim, complementares.

Vamos analisar o seguinte exemplo para diferenciarmos a noção de descrição e explicação e, ao mesmo tempo, apontarmos como Skinner possivelmente avança neste sentido. Exemplo: "Todas as vezes que um sujeito experimental emite uma resposta de pressão a barra, é liberada uma gota de água, assim é observado um aumento na freqüência e taxa de respostas". Notem que há somente uma descrição do comportamento e da quantificação da taxa de respostas - o registro de um evento sendo seguido por outro. Este exemplo caracteriza a posição inicial (década de 1930) de Skinner e sua relação direta com Mach e indireta com Hume, que afirmavam que somente podemos observar certos eventos sendo seguidos por outros e, logo, a probabilidade de ocorrência de eventos semelhantes no futuro em ocasiões semelhantes.

Por outro lado, uma aproximação com o selecionismo significa a necessidade de interpretação do comportamento em função de suas consequiências passadas. Deste modo, Skinner dá um passo além de Hume e de Mach, que apenas destacavam que determinados eventos são seguidos por outros eventos, e acrescenta o papel da retroação em seu sistema. De acordo com Skinner (1953/2000): "É clara a importância da retroação. Para que o condicionamento se efetue é necessário que organismo seja estimulado pelas conseqüências de seu comportamento" (p. 74). A descrição dos eventos passa a ser o "como" e a retroação seria o "porque" determinados 
eventos tendem a ocorrer novamente. Portanto, parece que somente descrever e quantificar os eventos que constituem um episódio comportamental não é mais suficiente para explicá-lo. É preciso que o comportamento, além de descrito, seja explicitado em termos de consequiências que retroagiram sobre esse no passado e aumentaram sua probabilidade de ocorrência no futuro. Skinner parece ter avançado em relação às propostas de Hume e Mach, porque pela pesquisa empírica conseguiu demonstrar o efeito de um evento sobre outro no caso do comportamento, a sensibilidade do organismo às conseqüências de sua ação sobre o ambiente e o efeito destas sobre o organismo. E não apenas a descrição de eventos seguidos por outros eventos e a formação do hábito.

Andery e cols. (2002), ao realizarem uma discussão inicial sobre as diferenças entre descrever e explicar no sistema explicativo skinnerino esclarecem que “(...) a descrição do evento comportamental trata dos fatores que o constituem em um determinado momento. A explicação desta constituição está na história e, no caso do modelo proposto por Skinner, em três histórias." (p. 160).

Ainda segundo Andery e cols. (2002), é possível observar que a posição de Skinner perante as idéias de descrição e explicação apresenta diferenças ao longo da sua produção. O que, no entanto, não foi suficiente para disseminação de discussões sobre as diferenças entre descrição e explicação entre os analistas do comportamento. Uns dos motivos disso é que grande parte dos analistas do comportamento recorre à descrição das relações funcionais como suficientes para explicar o evento comportamental e, com isso, não observam que descrever é apenas parte do trabalho e que esta posição sofreu alterações ao longo da obra de Skinner. Além disso, há de, no mínimo, desconfiar que quando um conceito advindo de uma área como a física é transposto para outra área, permanecerá intacto.

\section{Um Final Sem Final}

Quanto mais o behaviorismo radical se desenvolve (evolui), mais desdobramentos ele apresenta. E, para sermos coerentes com os pressupostos epistemológicos do behaviorismo radical, é preciso ter a consciência da não possibilidade de conclusão deste trabalho em termos finais, posto que o comportamento de quem realizou este trabalho está submetido ao princípio da seleção por conseqüências, portanto, é um comportamento que não tem uma finalidade ou um propósito. Podemos apenas dizer que o que este trabalho apresenta nada mais é do que comportamento verbal que, de acordo com sua história, experimentou variação e seleção, ou seja, essa é apenas uma versão de parte da história do desenvolvimento do behaviorismo radical. Mas, acima disso, falar que este é um final sem final demonstra justamente o que significa a transição do behaviorismo radical: complexidade!

\section{Referências}

Abib, J. A. D. (2004). O que é comportamentalismo? Em M. Z. S. Brandão, F. C. S. Conte, F. S. Brandão, Y. K. Ingberman, C. B. Moura, V. M. Silva \& S. M. Oliane (Orgs.), Sobre Comportamento e Cognição - vol.12 (pp. 52-61). Santo André: ESETec.

Andery, M. A. P. (1997). O modelo de seleção por conseqüências e a subjetividade. Em R. A. Banaco (Org.), Sobre comportamento e cognição - vol. 1: Aspectos teóricos, metodológicos e de formação em Análise do Comportamento e Terapia Cognitivista. (pp. 196-205). Santo André: ESETec.

Andery, M. A. P. \& Sério, M. T. A. P. (2001). Behaviorismo Radical e os determinantes do comportamento. Em H. J.Guilhardi, M. B. B. Nadi, P. P.Queiroz \& M. C. Scoz (Orgs.), Sobre o comportamento e cognição - vol. 7: Expondo a variabilidade (pp. 159-163). Santo André: ESETec.

Andery, M. A. P., Micheletto, N. \& Sério, M. T. A. P. (2002). O modelo de seleção por consequiências a partir de textos de B. F. Skinner. Em A. M. S. Teixeira, M. R. B. Assunção, R. R. Starling \& S. S. Castanheira (Orgs.), Ciência do Comportamento: Conhecere Avançar - vol. 2 (pp. 152-163). Santo André: ESETec.

Blanshard, B. (1974). The case for determinism. In: Determinism and Freedom (pp. 19-30). New York: Macmillan. (Trabalho original publicado em 1958).

Burtt, E. A (1983) As bases metafísicas da ciência moderna. Brasília: UnB. (Trabalho original publicado em 1932)

Carrara, K. (1998). Behaviorismo Radical: crítica e metacrítica. Marília: UNESP-Marília-Publicações.

Dittrich, A. (2004). Behaviorismo Radical, ética e política: aspectos teóricos do compromisso social. Tese de Doutorado, Universidade Federal de São Carlos, São Carlos.

Feyerabend, P. (1977) Contra o Método. (O. S. Mota \& L. Hegenberg, Trad.). Rio de Janeiro: Ed. Francisco Alves. (Trabalho original publicado em 1975)

Golgher, I. (1991). O universo físico e humano de Albert Einstein. Belo Horizonte. Oficina de livros.

Hume, D. (1980). Investigação sobre o entendimento humano. Em Os pensadores (A. Sérgio, Trad.). São Paulo: Abril Cultural. (Originalmente publicado em 1748)

Laurenti, C. (2004). Hume, Mach e Skinner: A explicação do comportamento. Dissertação de Mestrado, Universidade Federal de São Carlos, São Carlos.

Mach, E. (1960). The science of mechanics: a critical and historical account of its development. (T. J. McCormack, Trad). Illinois: Open Court. (Trabalho original publicado em 1893)

Micheletto, N. (2001). Variação e seleção: as novas possibilidades de compreensão do comportamento humano. Em R. A. Banaco (Org.), Sobre comportamento e cognição - vol. 1 . Aspectos teóricos, metodológicos e de formação em Análise do Comportamento e Terapia Cognitivista (pp. 116-129). Santo André: ESETec.

Moxley, R. A. (1999). The two Skinners, modern and postmodern. Behavior and Philosophy, 27, 97-125.

Moxley, R. A. (2001). The Modern/Posmodern context of Skinner's selectionist turn in 1945. Behavior and Philosophy, 29, 121-153.

Nagel, E. (1961). The structure of science: Problems in the logic of scientific explanations. New York: Harcourt, Brace \& World.

Rossi, P. (2001). O nascimento da ciência moderna na Europa. (A. Angonese, Trad.). Bauru: EDUSC.

Sério, M. T. A. P. (1990). Um caso na história do método científico: do reflexo ao operante. Tese de Doutorado, Pontifícia Universidade Católica de São Paulo, São Paulo.

Skinner, B. F. (1935). The generic nature of the concepts of stimulus and response. Journal of General Psychology, 12, 40-65.

Skinner, B. F. (1961).The concept of the reflex in the description of behavior. Em B.F Skinner (Org.), Cumulative Record: A selection of papers (pp. 319-346). New York: AppletonCentury-Crofts. (Trabalho original publicado em 1931). 
Skinner, B. F. (1966). The behavior of organisms: an experimental analysis. New York, Appleton-Century-Crofts. (Trabalho original publicado em 1938)

Skinner, B. F. (1984). Contingências do Reforço: uma análise teórica. Em Os pensadores, (R. Moreno, Trad.) vol, II. São Paulo: Abril Cultural. (Trabalho original publicado em 1969)

Skinner, B. F. (1984). Selection by consequences. Em A. C. Catania \& S. Harnad (Orgs.), Canonical papers of B. F. Skinner (pp. 477-481). The Behavioral and Brain Sciences, 7, 473-724. (Trabalho original publicado em 1981)

Skinner, B. F. (1991). O eu iniciador. Em B. F. Skinner (Org.), Questões Recentes na Análise Comportamental (A. Liberalesso
Néri, Trad.). Campinas: Ed. Papirus. (Trabalho original publicado em 1989)

Skinner, B. F.(2000). Ciência e comportamento humano. (R. Azzi e J. C. Todorov, Trad.). São Paulo: Martins Fontes. (Trabalho original publicado em 1953)

Skinner, B. F. (2002). Sobre o behaviorismo. (M. P. Villalobos, Trad.). São Paulo: Cultrix. (Trabalho original publicado em 1974)

Recebido em 25.04.2006

Primeira decisão editorial em 22.08.2007

Versão final em 27.09.2007

Aceito em 05.03.2008 